\title{
Hospitality Managers' Communication Practices
}

\author{
Judi Brownell \\ Cornell University \\ Published in International Journal of Hospitality \\ Management (1992), 11(2), 111-128.
}




\begin{abstract}
Recent research confirms that skill in oral and written communication is essential to effective management practice. Little is known, however, about the specific communication activities hospitality managers perform on the job. This study explores managers' perceptions of the frequency and difficulty of various organizational communication relationships and specific communication activities. Comparisons are made between the perceptions of middle and general managers in the hospitality industry with regard to individual and organizational communication practices. The results of this research have implications for practitioners, educators, and consultants as they work to improve the communication competence of hospitality managers.
\end{abstract}

Keywords: managerial communication, managerial activities, organizational communication 


\section{Hospitality Managers' Communication Practices}

\section{Introduction}

The nature of an organization's culture and its ability to respond appropriately to change is determined largely by the communication practices of its management team. It has been proposed that today's organizational leader is characterized not by specific personality traits or by the accomplishment of clearly defined tasks, but rather by the response he or she is able to elicit from others (Bass, 1981; Bass et al., 1987; Yukl, 1989). Leadership is dynamic and interactive, concerned with the business of shared values and visions, clear and motivational language, and appropriate communication strategies.

The hospitality managers who emerge as leaders in the 21st century are likely to be men and women who deal effectively with a multi-cultural workforce, who present their ideas clearly, and who are able to mobilize others around a common goal. Their competence and sensitivity will ultimately affect millions of employees, travelers, and customers worldwide.

There is little question that communication will play an increasingly vital role as hospitality managers meet a wide variety of human resources challenges in the decades ahead. In a competitive marketplace, effective service is often synonymous 
with effective communication; managers must not only make their messages clear, they must also develop and maintain positive relationships with both guests and employees. In a very real sense, effective management is effective communication; the business of leading and managing is accomplished largely through communication activities. A manager's communication skills, then, may well be his or her most potent tools for improving both individual and organizational performance.

In his 1988 review, stegman cited a variety of sources documenting the importance of communication skills in business; yet, there is little question that the specific communication practices of hospitality managers remain largely unexplored. Understanding the nature and requirements of managerial communication in an increasingly turbulent, uncertain, and multi-national environment becomes essential both for the educators and practitioners alike.

The purpose of this study was to learn more about hospitality managers' communication activities. Two groups were surveyed; middle managers (those whose titles were department or division manager) and general managers (those whose job title was general manager). Although a variety of questions was asked of respondents, the most significant pertained to (1) the frequency and perceived difficulty of communication among individuals in various organizational roles, (2) the frequency 
with which managers engaged in specific types of communication activities, and (3) the degree of skill they perceived other hospitality managers had with regard to each of these practices. The study was designed to provide information that would allow tentative comparisons to be made between the middle and general manager groups.

First, a summary of relevant background information is provided. Next, a profile of the two management populations is drawn. Results of the study are then examined, first in terms of organizational communication relationships and then in terms of communication activities. Middle and general manager groups are each discussed, after which the two populations are compared. Finally, findings are highlighted as they provide insights into daily managerial communication activities and directions for future research.

\section{Background}

Numerous studies throughout the past decades have focused on the traits or characteristics of managers and leaders (Stogdill, 1974; Bass, 1981; Lord et al., 1986; Carnevale et al., 1988). Related literature examines the nature of managerial work and seeks to identify what effective managers actually do on the job (Katz, 1952; Kotter, 1982; Hannan, 1978; Gabarro, 1985; Isenberg, 1984; Kanter. 1983; Horne and Lupton, 1965). In 
the vast majority of cases, this body of research confirms that mangers in general spend a good share of their time communicating, and that effective managers must communicate well.

In his 1986 review of the research to date, Hales identified nine recurring managerial tasks. Of these, seven are predominantly communication activities: leading, serving as a liaison, disseminating information, allocating resources, maintaining work flow, negotiating, controlling and directing subordinates (p. 95).

Emphasizing the need for effective communication in a slightly different manner, Carnevale and his colleagues explain that technological change and heightened competition drive what they call the 'upskilling' of work in America (1988, p. 23). More than ever before, managers must have strong interpersonal and oral communication skills.

Parallel to this research, there is a smaller but growing number of studies that have explored the characteristics (Arnaldo, 1981; Mullins and Davies, 1991; Seymour. 1985; Swanljung, 1981; Worsfold, 1989) and tasks (Ferguson and Berger, 1984; Ley, 1978; Hales and Nightingale, 1986; Dann, 1990; Umbreit and Eder, 1987) of hospitality managers. This research has also emphasized the importance of effective human relations skills to successful management practice. The case has 
repeatedly been made that because of the nature of service industries and the wide range of demands placed on their workers, hospitality managers' communication competence is particularly important. Service employees, as Worsfold (1989) repeats, require strong 'people skills' (p. 58). In many cases, social interactions are part of the 'product' itself.

The individuals who lead their organizations through such 21st century realities as changing values, internationalization, increased diversification, and rapid technological advance must be excellent communicators. These transformational leaders (Bass, 1991) must accurately gather organizational information, develop commitment and trust from their colleagues, and facilitate organizational learning and development. In all of these tasks, communication is the key.

Effective communication prevents costly mistakes that may result in lower productivity. Information that is incorrect, or that arrives too late, or that is lost entirely as it passes through the organization's hierarchy, adversely affects the bottom line. What may be less obvious is the consequence ineffective communication has for human resources management and interpersonal relationships within the organization.

The multi-national workforce, combined with increasing international travel, requires that successful managers develop skills to deal effectively with those whose backgrounds and 
assumptions are unlike their own. Within the organizational network, managers serve as links, communicating the perceptions of their workgroups to others whose interests, role, needs, and attitudes may be dissimilar. Poor communication, particularly in this environment, results in negative attitudes and low morale, high turnover and absenteeism, and increased stress (Thomas, 1991). Clearly, in service-oriented organizations already plagued by high turnover and characterized by collaboration, problem-solving, and uncertainty, effective managerial communication must be a high priority.

Yet, beyond broad generalizations, relatively little is known about the precise ways in which hospitality managers communicate on the job or the differences in communication activities between middle and general managers in the industry. Those who seek positions in hospitality management, and particularly those who aspire to move into top-level management positions, may find it useful to know more about the specific communication challenges hospitality industries pose. Business educators in general, and hospitality educators in particular, need guidelines from which to align their curricula with the realities of the work environment and the communication tasks that managers perform.

In an effort to address some of these needs, this study explores, from the perspectives of both middle and general 
managers, the nature of interactions among various organizational groups as well as the frequency and perceived difficulty of various managerial communication activities. This investigation follows in the tradition outlined by Hales (1986), who distinguished research focused on answering the questions: (1) With whom do managers work? and (2) What do managers do? Research methods are explained and a general description of the two populations is provided.

\section{Method}

This study relied on survey research, supplemented by telephone interviews. It began with five focus groups consisting of from four to seven practicing hospitality managers. These groups discussed their observations and personal experiences regarding managerial communication practices and challenges. Since previous research (Lewis and Reinsch, 1988) suggests that practitioner and academic understandings and definitions of communication-related variables may vary, the focus groups provide a check on research topics and direction. Videotapes and audiotapes were made of the focus group sessions, which were transcribed and used to direct the development of the final questionnaire.

The researcher and two assistants conducted a content analysis of the transcriptions of all focus group sessions to 
determine recurring themes. Information was coded on the basis of four categories that emerged from the data and which have been frequently noted in previous communication research: (1) the situation or context in which the communication took place, (2) the receiver's role or position, (3) the specific type of communication activity involved, and (4) the purpose of the communication, Although content analysis involves a degree of subjective interpretation, a very high level of rater agreement (92\%) increased the confidence level for accepting the following results.

The analysis of the coded transcripts indicated that two of the above variables appeared with much greater frequency and were perceived by participants to have more influence in determining the nature of communication encounters than the others; the participants' role relationship and the type of communication activity involved. I3oth were mentioned as important factors in almost all communication situations described by group members. The content analysis of focus group discussions further revealed four distinct organizational roles and eight communication activities.

An examination of the hospitality literature revealed the same four role categories that emerged from the focus groups: guests, hourly employees, middle managers, and the general manager. Consequently, two survey questions were designed to 
obtain information regarding the interactions among individuals occupying these organizational roles. In each case, the frequency and the degree of perceived difficulty in communicating are examined.

The final survey questions pertain to managerial communization activities. An extensive literature review of articles addressing the communication needs of managers (DiSalvo, 1976, 1980; Curtis et al., 1989; DiSalvo and Larson, 1987; Swenson, 1980; Stine and Skarzenski, 1979; Harris and Thomlison, 1983; Marshall and Cacioppe, 1986; Munter, 1983), coupled with an examination of the topics most frequently discussed in fourteen management communication textbooks, revealed a list of fifteen common management communication activities. Activities related specifically to the job search process were eliminated. In light of the content analysis performed on both the focus group transcriptions and the available literature, these fifteen topics were restructured into ten distinct management activities. Eight of these activities were generated by both the focus group transcripts and the literature searches. The remaining two (persuading and leading meetings), although appearing infrequently in the focus group transcripts, were included because they appeared with a high degree of frequency (in almost $90 \%$ of the cases) in the business communication texts surveyed. The ten topics include: 
(1) writing business memos;

(2) writing business letters;

(3) writing management reports;

(4) giving oral presentations;

(5) managing interpersonal conflict;

(6) listening;

(7) persuading;

(8) leading meetings;

(9) conducting performance appeals;

(10) giving feedback

A questionnaire was developed that requested information regarding the frequency with which managers found themselves engaged in each of these activities as well as the extent to which they perceived each as problematic or difficult for other hospitality managers generally. Respondents were asked to rate the ten activities on six-point Likert scales for each dimension.

Respondent profiles were also gathered to obtain a clear image of each sample. Information pertaining to the size of the property, the number of employees supervised, and length of time both in the industry and in the particular position was also recorded.

Alumni lists were generated by the Alumni Office at the School of Hotel Administration at Cornell University. Two populations of hospitality managers were identified, those in middle management and general managers. The pool of hospitality 
managers was limited to those holding supervisory positions in hotels, clubs, and resorts. Middle managers were defined as department or division heads; a general manager was identified as the top executive at a particular property holding the title of general manager. Only managers working in United states properties were targeted.

All individuals who fit the required profile were surveyed. As in any non-probability sampling method, statistics from the sample never duplicate exactly the characteristics of the entire population. Given the nature of this study, however, it is reasonable to assume that Cornell School of Hotel Administration alumni represent other industry managers adequately enough to provide useful information and to allow tentative generalizations to be made. The limitations of sampling methods are discussed more fully in a later section.

One hundred and thirty-three questionnaires were sent to alumni identified as general managers, one hundred and ninetyseven questionnaires were sent to middle managers. After two mailings, ninety-one general managers and one hundred and fiftythree middle managers responded. Response rates were 68\% and 78\% respectively. The sample size and response rate were large enough to allow generalizations to be made to the larger population with a reasonable degree of precision and accuracy. 


\section{Results}

The results of this study are discussed as they provide (I) information regarding managers' interactions in various organizational relationships and (2) insight into managers' perceptions of their specific communication activities. Before presenting these findings, however, more specific demographic information is provided for each of the two management groups.

\section{Profile of management population}

There were significant demographic differences between the middle and general manager populations. While $24 \%$ of the middle managers were women, women represented only $4 \%$ of the general management group. The ages of the two populations were also different. While 91\% of the middle managers were under thirtyfive, only 23\% of the general managers fell into this age range. Only 2\% of the middle managers were over forty-five, yet 65\% of the general managers were over forty-five. While no middle managers were over fifty-five, 8\% of the general managers were over sixty-five.

As might be expected, general managers had also worked in the industry far longer than middle managers. While over 70\% of the middle managers had worked in the industry for less than ten years, the same was true for only 10\% of the general managers. 
Twenty-eight percent of the middle managers had worked in the industry more than ten years, but none had worked over twenty years. This is in comparison to the general managers, where 91\% had worked in the industry for over ten years and 38\% had over twenty years of hospitality experience.

Generally, middle managers worked in larger properties than did the general managers. In the middle manager population, only 9.1\% of the respondents worked in properties with fewer than 200 rooms, and 22\% worked in properties with over 1000 rooms. When general managers were asked for information regarding the size of their properties, 14\% indicated that there were fewer than 200 rooms in their hotel, while only 6\% managed properties with over 1000 rooms. Thirty-eight percent of the middle managers worked in properties with 200-450 rooms; over 60\% of the general managers ran hotels with 200-450 rooms.

Spearman rank correlations were run for each of the above variable-gender, age, time in the industry, and size of property-and responses to the survey questions in each of the two general sections below, organizational communication relationships and communication activities. Correlations at a significance of 0.05 or greater are discussed in a following section. 


\section{Organizational communication relationships}

Much research has focused on communication networks and the nature of each relationship as individuals communicate up, down, and horizontally within the organization (Klauss and Rass, 1982; Rogers and Agarwala-Rogers, 1976; Monge et al., 1976; Richards, 1981; Larkin, 1980). Special attention, in fact, has been paid to 'managers in the middle' who serve as links between various organizational levels. Yet another relationship, characteristic of service industries, is the interaction between managers and guests. As mentioned earlier, there has also been a growing interest in the activities of general managers as well, particularly with regard to their influence on organizational members during the process of development and change (Daniel, 1985; Nicholas, 1983).

Two broad questions were asked of respondents to determine (1) the frequency and (2) the perceived difficulty of their interactions in various organizational relationships. Respondents provided their ratings on six-point Likert scales.

\section{Frequency of communication}

Responses to the question, 'How frequently do you believe each group communicates with one another?' were made on 6-point Likert scales. Reducing the number of categories to: infrequently (low: ratings of land 2), sometimes (medium: 
ratings of 3 and 4), and frequently (high: ratings of 5 and 6), makes it clear that general and middle managers perceive very different levels of communication at their properties. When asked about communication between middle and general managers, 93\% of the general managers rated their communication with middle managers as high, while only $62 \%$ of the middle managers said that they 'frequently' communicated with their general managers.

As might be expected, over 97\% of the middle managers said their communication with hourly employees was high. By comparison, 52\% of the general managers indicated that they communicated 'frequently' with hourly employees, although middle managers had a different perspective of the general manager/hourly employee interaction. Only 19\% of the middle managers indicated that communication between general managers and hourly employees was high, and 45\% rated the frequency as 1 or 2 .

When communication with guests was examined, almost 75\% of the general managers said they communicate 'frequently' with guests; this is compared with $46 \%$ of the middle managers who assigned this rating. In fact, over $20 \%$ of the middle managers indicated that middle manager communication with guests was low, while less than 6\% of the general managers said that general managers communicated with guests infrequently. 
As indicated on Table 1, middle managers' views of the general managers' communication did not always coincide with the general managers' responses. General managers appear to perceive more frequent communication between various groups than do middle managers. For instance, general managers perceive that middle managers communicate with both hourly employees and guests more frequently than do the middle managers themselves. Finally, middle managers appear to have a great deal of interaction with one another. Over $94 \%$ of the middle managers indicated that they communicated 'frequently' with their peers, and none of the respondents in this group rated their communication with other middle managers as infrequent.

\section{Difficulty of communication}

Respondents were also asked to indicate the degree of perceived difficulty with regard to eight communication relationships (Table 2). Notice that in this case the direction of the communication is taken into account in each pair. For convenience, we might again discuss ratings in three categories:

1 and 2 indicate little difficulty communicating, 3 and 4 indicate moderate difficulty communicating, and 5 and 6 indicate significant difficulty communicating.

When means were examined, both middle and general managers identified hourly employee to middle manager communication as 
the most troublesome, Approximately 40\% of the middle managers and just over $30 \%$ of the general managers rated this upward communication as 'very difficult'. However, while the middle managers' mean for hourly employee to middle manager communication was 4.92, general managers perceived significantly less difficulty-their mean for this relationship was 3.75 . The internal communications posing the fewest problems, both sets agreed, were between colleagues. Over 50\% of middle managers and 42\% of general managers indicated that colleagues had 'little difficulty' communicating with one another. This finding supports previous research of organizational communication and organizational networks in general (Frank, $1985)$

While this agreement is striking, there were important differences perceived by the two groups with regard to communication from middle managers to hourly employees, as well as communication between the middle and general manager groups. While the mean for middle managers was 3.97 (six represents the greatest degree of difficulty communicating) on the middle manager to hourly employee relationship, the mean for general managers answering the same question was 2.97, a full point lower. While only 6\% of the middle managers felt that they had 'little difficulty' communicating down to hourly employees, almost 25\% of the general managers rated the difficulty of the 
middle manager to hourly employee communication relationship as 1 or 2 .

Another relationship that was perceived differently by the two groups was upward communication from middle managers to the general manager. The middle manager mean for this question was one of the highest, 4.46. General managers perceived that middle managers had much less difficulty communicating with them; their mean was 3.01 . This was the greatest difference between middle and general managers' ratings in any category. The 3.01 indicated that general managers perceived that middle managers had just slightly more trouble communicating upward to them than they did communicating downward to the middle managers. Middle managers' again rated their communication with another group-guests-as more difficult (3.12 mean) than did the general managers (2.54 mean). While only $8 \%$ of the general managers believed that communication between middle managers and guests was 'very difficult', 19\% of the middle managers felt that these interactions were very difficult for them. In comparison, middle managers perceive that their general managers have little difficulty (mean 1.64) communicating with guests-a difference of 1.48. General managers saw much less difference between the difficulty they and their middle managers had communicating with guests. 
It appears that general managers perceived not only more frequent but also less problematic communication among various groups throughout their organizations than did the middle managers. The main exception to this is when general managers' self-perceptions are compared to the perceptions of middle managers with regard to the difficulty general managers have communicating with middle managers and with guests. In both of these cases, general managers perceived more difficulty communicating than did the middle managers.

After responding to questions pertaining to the various relationships within the organizational hierarchy, middle and general managers were asked to share their perceptions regarding specific communication activities-what they 'do' on the job.

\section{Managers' communication activities}

Managers were given a list of ten communication activities and asked to indicate, on six-point scales, the frequency with which they engage in each activity. They were then given the same list and asked how skilled they felt their peers are in each of the categories. Previous research indicates that phrasing the question in this manner is more likely to elicit a reliable response than if managers were asked to rate the degree of personal difficulty they experience. 


\section{Middle managers}

Table 3 provides a list of the ten communication activities according to middle managers' ranking of the frequency with which they engage in each activity. Persuading, writing business letters, and writing reports were the top-ranked activities, followed by managing conflict, listening, and giving feedback. Making oral presentations, leading discussions, writing memos, and giving performance appraisals were the activities middle managers performed least frequently.

When responses to the second question regarding perceived skill level are examined, we find that scores were not extreme, with means ranging from 2.64 to 3.52. Middle managers perceive that they are most skilled at managing conflict, persuading others, and performing appraisals. They believe middle managers are least skilled in listening, giving constructive feedback, and writing reports.

The difference scores for each activity, a comparison between the frequency a particular activity is performed and perceived skill level, are also interesting. These scores ranged from 0.06 to 1.93. In every instance, frequency means were higher than perceived skill level means. The most interesting findings are those that identified activities managers perform regularly and which are perceived as particularly problematic. Note that difference scores for writing business letters (1.93) 
and reports (1.90) and listening (1.91) are particularly high, followed by persuading (1.72) and giving feedback (1.67).

Spearman rank correlations among selected variables were also examined. Of particular interest are correlations above 0.05 level of confidence $(r=0.2)$. As might be expected, a high correlation was found between perceived skill levels in memo and letter writing $(r=0.718)$, and letter and report writing $(r=$ 0.699). The correlation between managing conflict and performing appraisals was also high $(r=0.643)$. In addition, the number of rooms in the manager's property and the frequency of writing memos correlated at $r=0.439$. The above suggests that managers make relatively little distinction between the skills needed to write letters and those required to write memos, and that there may be some fundamental requirements-such as confrontationcommon to both managing conflict and performing appraisals.

\section{General managers}

Similar to the middle managers. Table 4 indicates the general managers' rating of the ten communication activities according to the frequency with which each is performed on the job. The top-rated activity, with a mean score of 5.76 on a 6.0 scale, was listening. No one rated his or her listening as infrequent, and close to 75\% of the general managers gave 
listening the highest possible rating. General managers also indicated that they spent a great deal of time giving feedback (4.87) and persuading (4.85). Close behind were managing conflict (4.69) and writing business letters (4.63). General managers were least likely to write reports (3.99), perform appraisals (3.75), and make oral presentations (3.17).

General managers say they find it relatively easy to manage conflict, lead discussions, and persuade others. Activities found to be slightly more difficult include writing memos and letters, and listening effectively. The activities perceived as most troublesome were writing reports and making oral presentations, two tasks that general managers indicated they performed less frequently as well. Presentational speaking, in fact, was given the lowest rating both in terms of frequency performed (3.12) and difficulty (2.64). General managers appeared to discriminate among various tasks slightly more than middle managers, with means ranging from 2.64 to 3.79 .

When difference scores are examined, numbers range from 0.30 to 2.41. Table 4 presents the difference scores between the frequency and difficulty of each communication activity. The greatest difference score, 2.41, was related to listening. Other activities with difference scores above a 1.0 were giving feedback (1.58), writing business letters (1.47) and reports (1.10), and persuading (1.23). 
As might be predicted, there were once again high correlations among the perceived skill levels in several of the communication activities, particularly if writing (correlation between perceived skill level of writing memos and letters was $r=0.706$ ) and oral skills (correlation between perceived skill level of managing conflict and giving feedback was $r=0.658$ ) are examined separately. These correlations were very similar to those found in the middle management group. The highest correlation between a communication activity and a demographic variable, $r=0.401$, was between the number of rooms in the respondent's property and the frequency of providing feedback.

\section{A comparison of middle and general mangers' activities}

Greater differences occurred between the two management populations with regard to the frequency with which they performed various communication activities on the job than with regard to their perceptions of the difficulty they had practicing a particular skill. In fact, as noted, the range of mean scores for skill level was smaller in both populations than the frequency of communication range. The difference between middle and general managers' mean ratings for the frequency questions ranged from 0.03 to 1.21 while the greatest difference for the perceived skill level of any activity was 0.74. An examination of the frequency with which middle and general 
managers perform various activities reveals the greatest differences in making oral presentations (-1.12), writing reports $(-0.79)$, and listening (1.21).

While middle managers make presentations and write reports more often than general managers, the general managers indicate that they listen more than department and division managers. In fact, over 99\% of the general managers rated listening as either 5 or 6 on a 6-point scale. Thirty percent of the middle managers 'very frequently' (ratings of 5 or 6) give oral presentations, while the same is true of less than 20\% of the general managers. Over $60 \%$ of the middle managers also indicated that they very frequently write reports, while only 25\% of the general managers perform this type of activity very frequently.

Comparisons between middle and general managers with regard to perceived difficulty of the various communication activities reveals less striking results. Difference scores between mean ratings of middle and general managers with regard to perceived skill level were all under 0.50, with the exception of listening at 0.71 and leading discussions at 0.74 . Middle managers perceived themselves as considerably less skilled listeners than did the general manager group. Although means for the frequency of leading meetings were identical in both groups, general managers perceived themselves to be more skilled at this activity than did the middle managers. 
These results can now be considered in light of what we already know about hospitality management and managerial communication in organizations.

\section{Discussion}

Before the implications of this study are addressed, its potential limitations should be acknowledged. This research relied on reports from industry managers who were graduates of one hospitality management school. Although all members of this group were surveyed, non-probability sampling methods do not permit objective measurement of sampling variability and are therefore subject to greater error than probability sampling methods. The degree to which results of this study can be generalized to other hospitality managers depends upon how similar Cornell alumni are to other hospitality management groups.

Given the nature and purposes of this study, potential homogeneity of the sample was not perceived to be a significant concern. There is no reason to suspect a large variance between this sample and the larger population of hospitality managers with regard to factors that would influence the outcomes of the study. Cornell alumni can be assumed to confront, generally, the same communication situations and to require the same communication strategies as other practicing hospitality 
managers. This group is not unique in any way that would influence their responses to survey questions regarding communication relationships and activities. Conclusions drawn from this data, of course, must be considered preliminary and serve to direct our attention to topics and questions requiring further consideration. Some of the most useful conclusions are presented below.

As mentioned, when middle and general manager populations were analyzed, there were surprisingly few significant correlations between any of the findings and other variables of the work setting or the demographics of the participants themselves. Middle managers working in larger properties may write more memos than those in smaller organizations; the amount of feedback general managers provide may also vary according to property size. Otherwise, participant responses were not correlated with gender, age, time in the industry, or length of time in the job. In spite of this fact, there are several conclusions that can be drawn from the demographic information itself.

Demographics indicate that those who reach general management positions do so after many years in the industry. Recall that 91\% of the general managers had been working in the hospitality industry for more than ten years, and of that group 38\% had been working for twenty years or more. It follows that 
the general managers are also an older population than the middle manager group. This information may be important to new hospitality managers aspiring to run their own operations.

Previous studies on formal organizational communication networks have described the difficulties involved in upward, downward, and horizontal communication. Results from this study of organizational communication relationships draws our attention to some interesting points. As noted earlier, general managers perceive more frequent vertical communication between all groups than do middle managers. Contrasts between middle and general managers' perceptions of the degree of their own interactions are striking. General managers also believe that they communicate with both hourly employees and with guests far more frequently than middle managers suspect.

General managers perceive less difficulty in most organizational communication relationships than do middle managers. Several of these differences were statistically significant, including perceptions of the middle manager-hourly employee interaction by the two groups. The greatest discrepancy, however, was between general managers' perceptions of the degree of difficulty middle managers had communicating with them and the middle managers' view of this relationship. When we examine the activities managers say they spend most time performing, listening was ranked first by general managers 
while middle managers placed it fifth. There was a difference of 1.21 between the means of general and middle manager groups. In addition, middle managers perceived listening as the activity in which their peers were least competent.

An interesting comparison can be made between sending and receiving skills with regard to the two management groups. If we take the highest difference scores between middle and general managers with regard to the activities they report performing, the following pattern emerges:

$\begin{array}{llll} & \text { MM } & \text { GM } & \text { Diff } \\ \text { Listening } & 4.55 & 5.76 & 1.21 \\ \text { Presentations } & 4.29 & 3.17 & -1.12 \\ \text { Reports } & 4.78 & 3.99 & -0.79\end{array}$

Middle managers appear to present information, in both oral and written forms, more often than the general manager group. It appears that this group generates or collects and then presents or reports information to other organizational members. Middle managers also perform the traditional supervisory functions of controlling, delegating, organizing, and the like. These tasks require predominantly sender skills.

While middle managers operate in a sender or traditional 'communicator' role, the tasks associated with upper-level management appear to require more listening. General managers may be more involved with synthesizing, strategic planning, and decision-making; thereby, greater emphasis is placed on 
receiving the processing information. Even when not in a decision-making mode, however, general managers appear to seek information. This emphasis on listening is consistent with the findings of Ferguson and Berger (1984), who observed general managers and reported that they typically asked a lot of questions even in casual conversations and, although they attempted to influence others, they often did so indirectly. Yet, general managers believe they are only moderately skilled in an activity that they are engaged in continuously. It would appear that as individuals move into upper level management, their reliance on effective listening increases. This hypothesis is consistent with earlier work (Ried, 1983) on this subject. The importance of listening in organizations has been well-documented (Hunt and Cusella, 1983; Wolvin and Coakley, 1991); the implications of this need, both in middleand upper-level management, are particularly relevant for service industries.

Middle managers may not spend as much time listening as the general managers simply because of the nature of the hospitality environment. It is likely that middle managers find themselves in even more of a reactive mode; their job has been described as fragmented and largely unplanned. A special report on career burnout indicated that hospitality managers perform approximately 97 different tasks in their supervisory role while 
managers of other industries confront less than half that number (Lang, 1991). Under such circumstances, middle managers appear to recognize that their colleagues are generally poor listenersperhaps because a variety of 'sender tasks' demand the immediate attention of this group, such as persuading and managing conflict.

Middle managers indicated that they made oral presentations more frequently than the general managers. Although presentations were not one of the most frequently performed activities for either management populations, making oral presentations was perceived to be one of the more difficult tasks by both groups. Whether it is performed relatively infrequently because it is perceived as difficult is unclear; certainly, both groups may create or avoid opportunities to make presentations according to their degree of comfort with this type of communication activity.

In general, middle managers appear to operate in a largely verbal environment. This conclusion is consistent with earlier research on managerial communication (Kaplan, 1984; Lewis and Reinsch, 1988; Rhodes, 1985; Sypher et al., 1989). Although they frequently write letters and reports, hospitality managers send relatively few memos. The assumption might be made that this is because most of the information that needs to be communicated to 
subordinates or colleagues is done so verbally in face-to-face interactions.

Both groups, in fact, indicated that they spent more time writing business letters than either reports or memos. The perceived difficulty in writing internal memos, however, was much less than the difficulty perceived in writing letters and reports. Correlations among individual communication activities with regard to perceived difficulty, however, indicate that practitioners tend to perceive all writing tasks as similar in their level of difficulty and may not discriminate to the extent that communication educators do among the skills required for writing memos, letters, and reports. Written communication, in general, was perceived as more problematic than performing such activities as persuading orally and managing conflict, which were viewed among the least troublesome, although most frequent, activities by both groups.

\section{Future Research}

The need for additional research is evident. While this study surveyed a sizeable population, all respondents were graduates of the School of Hotel Administration at Cornell University. Other studies need to be conducted with more heterogeneous populations, including those managers who have not 
attended academic programs and those working in properties outside of the United States.

One of the most important factors for the effective communication-and effective management practice-is the accuracy of individuals' perceptions regarding their own and others' communication behaviors. Only when perceptions are accurate, and shared, can appropriate steps be taken to improve communication competence (Snyder, 1974; Schnake et al., 1990). Results of this study indicate that major discrepancies exist between the perceptions of middle and general managers with regard to a wide range of communication activities (also see Marshall and Cacioppe, 1986; Sypher and Zorn. 1986).

Further studies might address the adequacy of feedback channels throughout hospitality organizations, particularly those that provide general managers with information regarding the challenges and problems middle managers confront. In addition, research related to communication training programs might focus on the best methods of providing accurate and detailed feedback to participants regarding their own communication behavior so that their self-monitoring skills are further developed.

This study also explored hospitality managers communication activities. As current communication practices are identified, an important question becomes: What communication needs lie 
ahead as managers look to the 21 st century? It would seem that the importance of effective listening, for one, would increase as middle managers find themselves communicating with an increasingly diverse workforce and striving to provide quality service to guests from all parts of the world. It is likely that patterns of oral and written communication may change, too, with increased technology. Computer-generated messages and electronic mail may replace traditional forms of memos and reports.

The lack of women in general management positions is striking. The hospitality literature, and literature on women in management generally, points to a high attrition rate and greater difficulties moving up the career ladder (DeLuca, 1988; Gattiker and Larwood, 1990; Gregg and Johnson, 1990). Even though greater numbers of women are being admitted into academic hospitality management programs, they continue to be underrepresented in the workplace, particularly in upper management levels. This study confirms the findings of previous research and, although gender was not a key concern of this project, the data suggests that future studies might profitably examine women's communication activities and their relationship to retention and upward mobility in the industry.

The differences between the communication needs of middleand upper-level managers also deserves further exploration. This study suggests that these two groups may have different 
communication abilities and requirements. Do effective middle managers automatically make effective general managers, or are there communication competencies that are required of general managers that must be developed before middle managers can successfully assume upper-level leadership positions?

As we look more closely at those individuals who manage symbols, who inspire others toward a shared vision, and who perform the daily work of the organization, we are finding that communication competence distinguishes successful hospitality managers and leaders. This is not only an interesting discovery but an essential one, particularly as organizations undergo constant change and operate in ever-more turbulent, multicultural environments. Efforts directed toward learning more about management communication, and using that information to encourage more effective organizational practices, can help move the hospitality industry more smoothly into a promising but still uncertain future. 


\section{References}

Arnaldo, M. J. (1981) Hotel general managers: A profile. Cornell Hotel \& Restaurant Administration Quarterly 22(3) . 53-56.

Bass, B. M. (1981) Handbook of Leadership: A Survey of Theory and Research. Free Press, New York.

Bass. B. M., Avolio, B. J. and Goodheim. L. (1987) Biography and the assessment of transformational leadership at the world class level. Journal of Management 13, 7-20.

Carnevale, A., Gainer. L., Meltzcr, A. and Holland, S. (1988) Workplace basics: The skills employers want. Training and Development Journal 42, 283-290.

Curtis. D. B., Winsor, J. L. and Stephens. R. D. (I989) National preferences in business and communication education. Communication Education 38(1), 614.

Daniel. T. L. (1985) Managerial behaviors: Their relationship to perceived organizational climate in a high-technology company. Group \& Organization Studies 10(4), 413-428.

Dann, D. (1980) The nature of managerial work in the hospitality industry. International Journal of Hospitality Management $9(4), 319-334$.

DeLuca, M. (1988) Female lodging executives dealing with glass ceiling. Hotel and Motel Management 203(15), 10. 
DiSalvo, V. S. (1980) A summary of current research identifying communication skills in various organizational contexts. Communication Education 29(3), 283-290.

DiSalvo. V. S. and Larsen. J. K. (1987) A contingency approach to communication skill importance: The impact of occupation, direction, and position. The Journal of Business Communication 24(3), 3-22.

DiSalvo, V. S., Larson, D. C. and Seiler, W. J. (1976) Communication skills needed by persons in business organizations. Communication Education 25, 269-275.

Ferguson. D. H. and Berger, F. (1984) Restaurant managers: What do they really do? Cornell Hotel and Restaurant Administration Quarterly 25(1), 27-37.

Frank, A. D. (1985) Trends in communication: Who talks to whom? Personnel (4), 41-47.

Gabarro, J. J. (1985) When a new manager takes charge. Harvard Business Review May/June, 116-123.

Gattiker, U. E. and Larwood, L. (1990) Predictors for career achievement in the corporate hierarchy. Human Relations $43(8), 703-726$.

Gregg, J. B. and Johnson, P. M. (1990) Perceptions of discrimination among women as managers in hospitality organizations? FIU Hospitality Review 8(1), 10-22. 
Hales, C. (1987) What do managers do? A critical review of the evidence. Journal of Management Studies 23, 88-115.

Hales, C. and Nightingale, M. (1986) What are unit managers supposed to do? A contingent methodology for investigating managerial role requirements. International Journal of Hospitality Management 5, 3-1 1.

Hannan, M. (1978) Speech communication training needs in the business community. Central States Speech Journal 29, 163172 .

Harris, T. E. and Thomlison, T. D. (1983) Career-bound communication education: A needs analysis. Central States Speech Journal 34, 260-267.

Horne. J. H. and Lupton, T. (1965) The work activities of middle managers. The Journal of Management Studies 1, 14-33.

Hunt, G. and Cusella, L. (1983) A field study of listening needs in organizations. Communication Education 32(4), 393-401.

Isenberg, D. J. (1984) How senior managers think. Harvard Business Review November/December, 81-90.

Kanter, R. M. (1983) The Change Masters. Simon \& Schuster, New York.

Kaplan, R. E. (1984) Trade routes: The manager's network of relationships. Organizational Dynamics Spring, 37-52.

Katz, R. L. (1974) Skills of an effective administrator. Harvard Business Review 90-102. 
Klauss, R. and Bass, B. M. (1982) Interpersonal Communication in Organizations. Academic Press, New York.

Kotter, J. P. (1982) What effective general managers really do. Harvard Business Review 156-167.

Lang, J. M. (1991) Special report: Career burnout. Restaurant Business Spring.

Larkin, T. J. (1980) Network analysis as an investigative tool for organizational communication. Paper presented at the meeting of the International Communication Association, Acapulco, Mexico.

Lewis, M. H. and Reinsch, N. L. Jr (1988) Listening in organizational environments. The Journal of Business Communication 25(3), 49-67.

Lord, R. G., DeVader, C. L. and Alliger, G. M. (1986) A metaanalysis of the relation between personality traits and leadership: An application of validity generalization procedures. Journal of Applied Psychology 71, 402-410. Marshall, V. and Cacioppe, R. (1986) A survey of differences in communication between managers and subordinates. LODJ 7(5), $17-26$.

Monge, P. R., Boismier, J. M., Cook, A. L., Day, P. D., Edwards, J. A. and Kirste, K. K. (1976) Determinants of communication structure in large organizations. Paper 
presented at the meeting of the International Communication Association, Portland, Oregon.

Mullins, L. and Davies, I. (1991) What makes for an effective hotel manager? International Journal of Contemporary Hospitality Management 3(1), 22-25.

Munter, M. (1983) Trends in management communication at graduate schools. The Journal of Business Communication 20(1), 5-11. Nicholas, I. J. (1982) Organizational climate and strategic decision-making. Journal of General Management 7(3), 57-71. Rhodes. S. (1985) Specific listening skills important in organizations. Communication Research Bulletin 7(4), 1-2. Richards, W. D. (1981) A manual for network analysis. Institute for Communication Research, Stanford, California.

Rogers, E. and Agarwala-Rogers (1976) Communication in Organizations. Free Press, New York.

Schnake, M. E., Dumler, M. P., Cochran, D. S. and Barnett, T. R. (1990) Effects of differences in superior and subordinate perceptions of superiors' communication practices. The Journal of Business Communication 27(1) . 37-50.

Seymour, D. (19SS) An occupational profile of hoteliers in France. International Journal of Hospitality Management 4, $3-8$.

Snyder, M. (1974) The self-monitoring of expressive behavior. Journal of Personality and Social Psychology 30, 526-537. 
Stegman, J. D. (1988) The importance of managerial

communication: An annotated bibliography. The Bulletin $51(3), 25-26$.

Stine, D. and Skarzcnski, D. (1979) Priorities for the business communication classroom: A survey of business and academe. The Journal of Business Communication 16, 15-30.

Stogdill, R. M. (1974) Handbook of Leadership: A Survey of Literature. Free Press, New York. Swanljung, M. (1981) How hotel executives made the climb to the top. Cornell Hotel and Restaurant Administration Quarterly (2), 30-34.

Swenson, D. H. (1980) Relative importance of business communication skills for the next ten years. Journal of Business Communication 17(2), 41-49.

Sypher, B. D., Bostrom, R. N. and Seibert. J. H. (1989) Listening, communication abilities, and success at work. The Journal of Business Communication 26(4), 293-303.

Sypher. B. D. and Zorn, T. E. (1986) Communication related abilities and upward mobility: A longitudinal investigation. Human Communication Research 12, 420-431.

Thomas, J. J. (1991) Prescriptions for managerial burnout within hotel food and beverage operations. Unpublished MPS monograph, Cornell University.

Umbreit. W. T. and Eder, R. W. (1987) Linking hotel manager behavior with outcome measures of effectiveness. 
International Journal of Hospitality Management 6(3), 139147.

Wolvin, A. D. and Coakley, C. G. (1991) A survey of the status of listening training in some Fortune 500 corporations. Communication Education 40(2), 152-164.

Worsfold, P. (1989) A personality profile of the hotel manager. International Journal of Hospitality Management 8(1), 5162.

Yuki. G. A. (1989) Leadership in Organizations. Prentice-Hall. Englewood Cliffs, NJ. 
Table 1. A comparison of middle and general managers' perceptions of communication frequency

\begin{tabular}{lcccccc}
\hline & \multicolumn{3}{c}{ Middle manager } & \multicolumn{3}{c}{ General Manager } \\
(Percentages & Inf & Sometim & V. & Inf & Sometim & V. \\
l & & es & freq & & es & freq \\
\hline a. Hr emp and & - & 2.7 & 97.3 & - & 0.7 & 99.3 \\
MM & & & & & & \\
b. Hr emp and & 44.9 & 26.2 & 18.7 & 24.3 & 23.6 & 52.1 \\
GM & & & & & & 8.2 \\
C. MM and MM & - & 5.7 & 94.3 & - & 91.8 \\
d. MM and guest & 22.6 & 31.3 & 46.1 & 11.2 & 32.1 & 56.7 \\
e. GM and guest & 7.8 & 55.7 & 36.5 & 5.7 & 20.1 & 74.2 \\
f. MM and GM & 14.3 & 23.5 & 62.2 & - & 6.6 & 93.4 \\
\hline
\end{tabular}


Table 2. A comparison of middle and general managers' perceptions of communication difficulty

\begin{tabular}{lccccc}
\hline (Mean scores) & $\begin{array}{c}\text { Middle } \\
\text { manager }\end{array}$ & SD & General & SD & Diff \\
& manager & & \\
\hline a. Employee to MM & 4.92 & 0.83 & 3.75 & 0.95 & 1.17 \\
b. MM to employee & 3.97 & 1.40 & 2.97 & 1.30 & 1.00 \\
c. Colleague to & 2.77 & 1.07 & 2.52 & 1.16 & 0.25 \\
colleague & & & & & \\
d. Employee to guest & 3.33 & 1.62 & 3.27 & 1.21 & 0.06 \\
e. MM to guest & 3.12 & 1.53 & 2.54 & 0.87 & 0.58 \\
f. GM to guest & 1.64 & 1.14 & 2.06 & 1.17 & - \\
g. MM to GM & 4.46 & 1.04 & 3.01 & 0.97 & 1.41 \\
h. GM to MM & 2.31 & 0.90 & 2.93 & 1.02 & - \\
\end{tabular}


Table 3. Middle managers' communication activities (mean scores and standard deviations)

\begin{tabular}{llllll}
\hline Activity & Frequen & SD & Skill & SD & (Differe \\
& cy & & level & & nce) \\
\hline Persuading & 5.12 & 0.54 & 3.40 & 0.93 & 1.72 \\
Business letters & 4.89 & 1.11 & 2.96 & 0.99 & 1.93 \\
Writing reports & 4.78 & 0.84 & 2.88 & 0.73 & 1.90 \\
Managing & 4.75 & 1.07 & 3.52 & 0.90 & 1.23 \\
conflict & & & & & \\
Listening & 4.55 & 0.63 & 2.64 & 0.72 & 1.91 \\
Giving feedback & 4.54 & 1.13 & 2.87 & 1.02 & 1.67 \\
Presentations & 3.81 & 0.66 & 2.94 & 1.07 & 1.31 \\
Leading & 4.00 & 0.95 & 3.00 & 0.86 & 1.00 \\
discussion & & & & & 0.96 \\
Writing memos & 3.72 & 0.83 & 3.17 & 0.91 & 1.26 \\
Appraisals & 3.42 & 1.31 & 3.36 & 1.06 \\
\hline
\end{tabular}


Table 4. General managers' communication activities (mean scores and standard deviations)

\begin{tabular}{lccccc}
\hline Activity & $\begin{array}{c}\text { Frequen } \\
\text { cy }\end{array}$ & SD & Skill & SD & (Differe \\
& 5.76 & 0.47 & 3.35 & 1.06 & 2.41 \\
\hline Listening & 4.87 & 1.07 & 3.29 & 1.11 & 1.58 \\
Giving feedback & 4.85 & 0.96 & 3.62 & 1.00 & 1.23 \\
Persuading & 4.69 & 1.15 & 3.78 & 0.89 & 0.86 \\
Managing conflict & 4.63 & 1.05 & 3.14 & 1.10 & 1.47 \\
Business letters & 4.17 & 1.29 & 3.39 & 0.93 & 0.78 \\
Memos & 4.03 & 1.15 & 3.74 & 1.02 & 0.30 \\
Leading meetings & 3.99 & 0.86 & 2.89 & 0.94 & 1.10 \\
Writing reports & 3.75 & 1.29 & 3.09 & 1.12 & 0.66 \\
Appraisals & 3.17 & 0.91 & 2.69 & 0.69 & 0.48 \\
Presentations & & & & \\
\hline
\end{tabular}


Table 5. Comparisons between general and middle managers' communication activities

\begin{tabular}{lcccccc}
\hline & \multicolumn{3}{c}{ Frequency } & \multicolumn{3}{c}{ Skill level } \\
Activity & GM & MM & (Diff) & GM & MM & (Diff) \\
\hline Listening & 5.76 & 4.55 & 1.21 & 3.35 & 2.64 & 0.71 \\
Feedback & 4.87 & 4.54 & 0.33 & 3.29 & 2.87 & 0.42 \\
Persuading & 4.85 & 5.12 & -0.27 & 3.62 & 3.46 & 0.16 \\
Mgmt conflict & 4.69 & 4.75 & -0.06 & 3.78 & 3.52 & 0.26 \\
Bs letters & 4.61 & 4.89 & -0.28 & 3.14 & 2.96 & 0.18 \\
Memos & 4.16 & 3.72 & 0.44 & 3.39 & 3.17 & 0.22 \\
Lead discussion & 4.03 & 4.00 & 0.03 & 3.74 & 3.00 & 0.74 \\
Reports & 3.99 & 4.78 & -0.79 & 2.89 & 2.88 & 0.01 \\
Appraisals & 3.75 & 3.42 & 0.33 & 3.09 & 3.36 & -0.27 \\
Presentations & 3.17 & 4.29 & -1.12 & 2.69 & 2.94 & -0.25 \\
\hline
\end{tabular}

